\title{
Implementing Social Justice Practices Online: Lessons Learned from Teaching and Advising Dissertations in Practice During the COVID-19 Pandemic
}

\author{
Karie Huchting \\ Loyola Marymount University \\ khuchtin@lmu.edu \\ Rebecca Stephenson \\ Loyola Marymount University \\ rebecca.stephenson@lmu.edu
}

\begin{abstract}
This essay documents the lessons learned from the transition to teaching research methods courses and advising EdD doctoral students online due to the COVID-19 pandemic. This discussion is set against the backdrop of developing a new fully online EdD Program in educational leadership for social justice at the institution, wherein the online transition due to COVID-19 offered an opportunity to assess effective pedagogy, student community and engagement, and workload expectations. In our analysis of the transition to teaching online, we applied Hammond's (2020) framework, which highlights design elements that promote agency for independent learning. We overlay the realities of teaching and advising adult students who are working full-time and managing home-life responsibilities in addition to pursuing their EdD degree. Unresolved questions and future directions for the culturally responsive and socially just online Education Doctorate are explored.
\end{abstract}

\section{KEYWORDS}

social justice education, distance learning, COVID-19, EdD programs

As professors at a CPED-affiliated institution, we have taught qualitative and quantitative research methods courses in our fully face-to-face, cohort-based, EdD program for the past 10 years. When the university closed the campus in mid-March 2020, we found ourselves transitioning our courses and dissertation advising online. Together with our students, who were simultaneously enrolled in doctoral studies while teaching and leading K-12 schools and working as university student affairs practitioners, we were thrust into a place of collective uncertainty: the familiar spaces and routines of school replaced with stopgap solutions for distance learning. These "pandemic pedagogies" differed from previous models for face-toface instruction, online instruction, or blended learning (Williamson et al., 2020), and required adjustment to new expectations and activities. This essay will underscore how EdD faculty and students adapted to and improved upon pandemic pedagogies. Furthermore, this essay will consider how the global pandemic created an opportunity for our program to re-assert a holistic vision for education that uplifts equity, inclusion, and agency-hallmarks of a socially just education-in ways that acknowledge and engage the contemporary context in which we are living.

\section{PROGRAM DESCRIPTION}

The EdD program highlighted in this essay focuses on educational leadership for social justice. Our definition of social justice is linked to the urban educational context in which we and our students work as well as the university's identity as a Catholic, Jesuit institution. The three-year program includes three research methods courses focused on preparing students for subsequent Dissertations in Practice (DiP). These courses cover content including literature searches and academic writing, quantitative, qualitative, and mixedmethod research designs, and techniques for data collection and analysis. During year three of the program, students are required to produce an individual dissertation, focused on a Problem of Practice, under the guidance of a dissertation committee. In alignment with CPED, which encourages high quality, rigorous practitioner preparation with a strong background in educational theory and recent research to inform one's practice, this program attempts to prepare students for their DiP focused on "a persistent, contextualized, and specific issue embedded in the work of a professional practitioner, the addressing of which has the potential to result in improved understanding, experience, and outcomes" (CPED, 2019, n.p.).
New articles in this journal are licensed under a Creative Commons Attribution 4.0 United States License. Program and is cosponsored by the University of Pittsburgh Press.

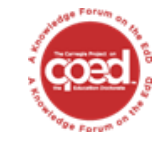

This journal is supported by the Carnegie Project on the Education Doctorate: A Knowledge Forum on the EdD (CPED) cpedinitiative.org 


\section{FRAMEWORK}

The purpose of this essay is to reflect on the lessons learned from transitioning research methods courses and dissertation advising online during the COVID-19 pandemic. While we would argue there is no good time for a global pandemic, the timing of our university's switch to online instruction (expected to continue through at least summer 2021) and, in particular, the lessons learned about what equitable, inclusive, and student-centered education needs to look like under these conditions, was serendipitous given our plans to launch a fully online EdD program in January 2021. The collective uncertainty experienced by faculty and students due to COVID-19 provided an opening to re-examine, re-calibrate, and re-imagine what a socially just EdD program can and should look like.

Drawing on the constructivist philosophy that animates our practice in the School of Education as well as the Jesuit notion of cura personalis (personalized care of the whole person) central to our university mission, our initial approaches to pandemic pedagogies concentrated on co-constructing with students an approach to our work together that met their needs and accommodated their obligations. As most of our students are K-12 educators and school leaders or student affairs professionals in higher education, the amount and intensity of their professional obligations had increased significantly following school closures and stay-at-home orders. In addition, our program's commitment to recruiting and supporting a diverse cohort-in terms of race, ethnicity, gender, sexuality, ability, age, professional background, and experience in higher education-means that our students' contexts and circumstances are also diverse. They live in communities throughout the Los Angeles area, some of which continue to experience disproportionate rates of COVID-19 infections; some are parents of school-aged children and/or caretakers for ageing parents; some were furloughed or laid off from their positions during the spring semester. While we as faculty are accustomed to shaping instruction to meet students' diverse needs, many of the needs taking the spotlight during the spring semester were new to all of us.

In order to understand and guide our instructional and programmatic choices, we turned to Hammond's framework for culturally responsive education (2020) to review the ways in which our online delivery truly embraces culturally responsive techniques. Hammond (2020) distinguishes between socially just education, which focuses on cultivating critical consciousness by responding to the social political context, and culturally responsive education, which promotes individual agency and independent learning for students who have been marginalized by building cognitive capacity and challenging dominant narratives (Major, 2020). While our program's curriculum focuses primarily on social justice education, the shift to online learning necessitated our intentional focus on culturally responsive education to address the loss of social and educational structures that typically support our students' learning.

\section{LESSON LEARNED}

\section{Teaching Methods while the World Burns}

Shortly after the campus was closed in response to stay-athome orders, the university launched a set of websites entitled "Keep Teaching Wherever You Are" (for faculty) and "Keep Learning Wherever You Are" (for students). These sites, created by the university's Information Technology Services office, provided information on remote teaching and learning, including available trainings, software, and applications, as well as university policies related to online instruction. At first blush, the message to "Keep Teaching" or "Keep Learning" regardless of the context in which you found yourself at the start of the pandemic, seems to prioritize continuity over student-centeredness and cultural responsiveness. And, indeed, many of our initial "pandemic pedagogies" were efforts to provide continuity rather than to be culturally responsive.

For example, our program places great value on community and supports a vision of a community of scholar-practitioners through a cohort model. During the required distance learning in the spring due to COVID-19, we attempted to preserve the face-to-face cohort and communal experience via synchronous online course meetings. It quickly became apparent that replicating the offline experience, in which students take two, two-and-a-half hour classes back-to-back on Monday evenings, was neither meeting students' educational needs nor responding to the trauma we were all experiencing. We recognized that adding lengthy videoconference classes to students' home-life (i.e., small children, aging parents) and employment responsibilities (i.e., leading schools/districts through COVID-19 transitions) was not a preservation of community or "normalcy," but an unnecessary burden.

Learning from this experience, we pivoted to emphasizing asynchronous work. Drawing upon prior training in instructional design for asynchronous online teaching, we began crafting assignments and instructional materials to scaffold students' work. Among the resources we created were a series of video interviews with colleagues and alumni discussing their area of research and DiPs, mini video lectures to reinforce content from readings, and small-group assignments designed to foster collaboration and community. The flexibility and personalization facilitated by asynchronous delivery aligns with the promotion of individual agency and independent learning as discussed by Hammond (2020). Through flexible and individualized asynchronous work, we focused on the idea of teaching/learning "wherever you are," with "wherever you are" referring not only to our distributed locations but also to students' cognitive and emotional capacities for learning during this time. Additionally, this pivot helped us answer a question that we had asked many times without arriving at an answer: "Do students really need to learn research methods now?" Given the scale of suffering and injustice related to COVID-19, we frequently felt the answer was no; however, culturally responsive education, with its emphasis on accelerating the learning of marginalized students, tells us the correct answer is actually yes. Removing students' opportunity to learn and advance in their program or teaching online using offline techniques, while efficient and possibly necessary during pandemic pedagogies, does not reflect cultural responsiveness. Changing instruction to meet students "where they are," encouraging students to engage with the social context in which they live, while being flexible and accommodating real life, does.

For example, rather than teaching statistics synchronously via Zoom, how-to videos demonstrating the steps of analyzing data were pre-recorded using screen capture and posted to the online learning platform. Students could access the video throughout the week and watch it as many times as needed. Students were then tasked with manipulating a provided dataset to practice replicating the steps they had just seen in the video. Each week students were asked to watch a new how-to video, demonstrating a new statistical technique, and complete a series of analyses using the provided dataset. Students 
commented that the videos provided an opportunity to pause and rewind as needed to grasp the content fully. During the weekly Zoom meetings, synchronous time was spent reviewing the correct analyses and checking for understanding. In fact, more time was available to discuss the best ways of communicating findings to an audience, rather than on direct instruction of how-to run the analyses. Students appreciated the chance to ask questions and seek clarifying information during the synchronous meetings, indicating that the experience felt more tailored to their needs. These synchronous meetings did not last as long as a traditional 150 minute face-to-face class session because the majority of work had been completed asynchronously prior to the meeting. Students expressed appreciation in their course evaluations for treating them "like professionals," allowing them flexibility to still attend to their home-life and work responsibilities.

While creating materials to deliver instruction asynchronously took several hours of work on the part of the professors, pedagogically, one of the benefits of moving direct instruction to predominantly asynchronous delivery was the opportunity to spend synchronous class time checking in about content and navigation of upcoming expected work. These briefer synchronous meetings thus allowed for professors to frontload the subsequent weeks' worth of work, activate prior knowledge by connecting future expectations to ongoing projects and content, and demonstrate how to navigate the remaining course expectations, including the online platform. Most importantly, these briefer synchronous sessions provided an opportunity to check in about students' well-being. Students shared in the end of term course evaluations that they appreciated the chance to "check in" with the professor and with each other. Hearing about others' experiences during the COVID-19 pandemic, both with work and with doctoral studies, afforded the cohort an opportunity to maintain a sense of community.

In addition to the professor-led direct instruction videos provided online, students were invited to work together in smaller groups and dyads throughout the summer course. For example, one assignment required a group of five randomly assigned students to hold and record a team discussion about course readings. Students were instructed to complete the readings and arrange a time to meet with their team to hold the discussion, which they were to record (audio and video) and post to the discussion page in the online learning management platform. Students were provided ample time to finish the assignment and discussion prompts were provided to stimulate the conversation and encourage students to connect themes across the readings and to their daily practice. The professors enjoyed "watching" an actual discussion of the readings compared to reading a discussion board post and students enjoyed watching other teams' discussions. Further, professors were easily able to identify challenges with content knowledge based on the discussion, which they were able to clarify thematically during the synchronous course meetings. In fact, questions arose naturally during the team discussions allowing students to offer their responses and understanding, while the professors made note to clarify such questions during synchronous meetings. The students also shared that they sincerely enjoyed the experience of working in smaller groups to discuss material because the assignment afforded them an opportunity to build community in addition to challenge their thinking and extend their understanding. Finally, students offered their observation that this activity felt more authentic than posting a written response to a discussion board thread.
In another assignment, students were assigned to complete a recorded presentation with a chosen partner. In this activity, students delivered a pre-recorded presentation with visual slides, thereby requiring that the partners plan and work together prior to giving the presentation. Presentations were then posted to the class online learning management system and students were required to watch each other's presentations and provide feedback. Students shared how this assignment forced them to really learn the content since they were asked to publicly demonstrate their command of the concepts in a video presentation. Valuable synchronous class time was therefore not spent on listening to the presentation live but rather clarifying questions and extending the conversation by highlighting themes across presentations. Such examples certainly align with Hammond's notion of promotion of individual agency and independent learning (2020) without sacrificing the sense of community.

Taken together, the lessons learned about teaching research methods courses online included: (a) continuity is not the only goal: teaching the same class on and offline is ineffective and, more importantly, not responsive to students' needs; (b) a sense of community can be bolstered by brief but intentional synchronous meetings; and (c) online learning requires maximum flexibility from both faculty and students, which enhances the co-construction of knowledge. Feedback from students was gathered via end of term course evaluations and a weekly survey on how the courses were going. Feedback suggested that students appreciated the flexibility and professionalism of the asynchronous course delivery. Synchronous time was still required in order to promote community and time together but these precious meetings were utilized differently to focus instead on content clarification, check-ins, and community building. Thus, the move online due to COVID-19 highlighted how the notion of community can look different via distance learning yet still provide a feeling of individualized attention and care via the flexibility provided by asynchronous content delivery. Such lessons have implications for the newly designed fully online program where considerations related to creating community will be required for students potentially accessing the program across various time zones.

\section{Dissertation Advising and Adjusting}

The three-year timeline of the EdD program results in our doctoral students conducting fieldwork to collect dissertation data during the spring and summer months for their DiP. As such, a number of students' projects were drastically impacted in March of 2020 by school closures and physical distancing required by health officials to curb the spread of COVID-19, including students who received approval to conduct field research days before our university - and our entire geographic area-shut down. Again, the question of whether students really needed to do this work now arose. However, in order to be responsive to students' needs-not just immediate needs to adjust the studies, but their need to have the challenges they faced validated-we assisted students in pivoting their plans for data collection to work within new restrictions and to meet new needs within the research contexts. For example, one student, who was planning to conduct an on-campus ethnography involving a specific population of international students not only faced the challenge of the campus closure, but also needed to address the fact that many of her participants left the U.S. and were unable to return. As it became clear that students would not be 
returning to campus in the fall, we helped her adjust her study to focus on interviews conducted via videoconference rather than participant observation. While the research will certainly have different outcomes given the methodological changes, this approach responds to the student's needs as well as the needs of her participants. Another student pivoted her Youth Participatory Action Research project, planned to be conducted on campus at her place of employment, to instead take place online, requiring her to rethink the ways in which participants would engage and communicate. Other students experienced challenges related to recruitment, as communities and populations they intended to include were no longer accessible. Finally, one student recognized that the problem of practice she had planned to study was being eclipsed by a new problem of practice-implementing online learning. She completely shifted her project in the early weeks of the pandemic in order to focus on understanding her school's process for meeting the needs of their students.

These examples of DiPs showcase how dissertations can cultivate critical consciousness, which Hammond (2020) asserts is social justice education. This critical consciousness can be even more impactful by engaging in work in ways that are responsive to the social political context-an opportunity COVID-19 presented to our doctoral students and faculty. Encouraging creativity in data collection procedures further provided students with an opportunity to practice independent learning and agency. Meanwhile, faculty were often discussing ways to navigate the social political contexts to assist students with rapid changes to their dissertation topics, data collection procedures, and approval processes. Thus, both students and teachers were forced to navigate the social political context together, which we believe led to greater critical consciousness by determining the best process of data collection that addressed the needs of the broader community. We remain hopeful that such lessons learned from navigating DiPs during the COVID-19 pandemic will continue to inform data collection procedures for future students.

Meanwhile, students in their final year of the program were attempting to graduate in May of 2020 and many were scheduling their dissertation defenses when all activities were moved online due to COVID-19. Interestingly, while defenses are often viewed by students as nerve-wracking milestones, technological uncertainty on the part of faculty led to feelings of anxiety as well. Students, who arguably already were more technologically proficient or learned to navigate technology more quickly in their daily practices as educational professionals, often taught the faculty how to use the technology. A common experience was having students teach the faculty how to use the "breakout room" feature, for example, to allow private dissertation faculty committee deliberations. Thus, there was a more communal feeling to the dissertation defenses in the spring of 2020, marked by the shared experience of nerves for both students and faculty, who had to collaborate and assist each other technologically. Such experiences flip the traditional power dynamics associated with defenses and challenge the dominant narrative and division between teacher and student. At this stage of the student's career, especially, such moments should celebrate the students' transformation into a prosumer of research (Toffler, 1980) and demonstrate Hammond's notion of culturally responsive education that promotes agency and challenges the dominant narrative of education.

\section{CONCLUSION}

When the university campus closed in March 2020, our initial pivot to online instruction focused on continuity-fulfilling the mandates to "keep teaching" and "keep learning" despite the unprecedented circumstances presented by COVID-19. As we have continued teaching and learning online, however, we have had the opportunity to reimagine education for our EdD students in ways that are responsive to the current realities of the social political context and to their individual needs. Implications for other EdD educators stem from the lessons we learned from shifting instruction and advising online during the pandemic.

First, we learned that while continuity is important in terms of offering EdD students opportunities to develop critical consciousness through their coursework and research, it is also important to recognize the critical consciousness that develops by living through a crisis such as a global pandemic-particularly when, as we have seen during the COVID-19 pandemic, that crisis brings into clear focus issues of systemic injustice. In shifting our focus from continuity to responsiveness, we have seen the value of providing opportunities to share experiences or discuss the impacts students feel as well as those they observe in their practice, adjusting instruction in ways that acknowledge and validate the difficulties of the current moment.

Second, we learned from our students that a sense of community must be curated in intentional ways, mindful of their greater responsibilities as school leaders and caretakers, while also attending to their doctoral work. EdD students in our program are working professionals in the "sandwich generation" (Parker \& Patton, 2013) - simultaneously caring for young children and older parentswho lost the concentrated space and time to singularly focus on doctoral work during dedicated time on campus. The sense of community from their doctoral cohort shifted along with their daily routines, making long synchronous class meetings ineffective.

Finally, the pandemic created the scenario where we, as faculty, were learning with and from our students, who demonstrated flexibility and creativity in redesigning their DiP due to COVID-19. By learning together, we saw the traditional notions and power dynamics of education disrupted, offering an opportunity for constructivist education to truly take shape, flattening the power hierarchy often associated with doctoral work. Despite (or perhaps because of) the collective uncertainty COVID-19 has caused, we have been challenged to craft and test new approaches to studentcentered education that also sets them up to impact practice. These student-centered practices encourage independent learning and agency-skills and dispositions required by social justice leaders beyond the EdD degree. Indeed, these practices will need to be continually evaluated, as the needs of our students and the social political context are likely to continue to shift. And we will need to continue to monitor how such changes in program pedagogy impact students' leadership praxis. We remain committed and inspired by the intrinsic motivation demonstrated by our students, who have chosen to continue their doctoral work during the pandemic because they believe in the power of the DiP to transform their communities for the better.

In conclusion, this reflective essay about our online teaching and advising experiences during COVID-19 offered a chance for us to engage the question: What does socially just education in an EdD program truly look like? If a socially just education is one that cultivates critical consciousness by responding to the social political 
context (Hammond, 2020), then pedagogy that promotes individual agency, independent learning, and cognitive capacity building, mindful of the historical oppression of marginalized communities-or culturally responsive education-offers a method to guide our practice. Within an EdD program where students are invited to engage problems of practice impacting their educational contexts, culturally responsive pedagogy should offer opportunities for students to challenge dominant narratives and transform their mindsets, encouraging these educational leaders to focus on equitable outcomes for students who have been historically marginalized. Thus, culturally responsive pedagogy lends itself to online learning allowing students to cultivate the knowledge, skills, and dispositions required to transform educational communities for greater access and equity. This is the hallmark of a socially just education.

\section{REFERENCES}

Carnegie Project on the Education Doctorate [CPED]. (2019). The CPED framework. http://www.cpedinitiative.org/page/AboutUs

Caverly, D., \& MacDonald, L. (1999). Techtalk: Asynchronous distance development education. Journal of Developmental Education, 23(2), 3637.

Hammond, Z. (2020). Moving beyond the packet [Webinar]. https://crtandthebrain.com/covid19-webinars/

Major, A. (2020). How to develop culturally responsive teaching for distance learning. KQED Mind/Shift. https://www.kqed.org/mindshift/55941/howto-develop-culturally-responsive-teaching-for-distance-learning

Parker, K., \& Patton, E. (2013). The sandwich generation: Rising financial burdens for middle-aged Americans. PEW Research Center. https://www.pewsocialtrends.org/2013/01/30/the-sandwich-generation/

Paulus, T., Myers, C., Mixer, S., Wyatt, T., Lee, D., \& Lee, J. (2010). For faculty by faculty: A case study of learning to teach online. International Journal of Nursing Education Scholarship, 7(1), 1-17.

Toffler, A. (1980). The third wave. Bantam.

Williamson, B., Eynon, R., \& Potter, J. (2020). Pandemic politics, pedagogies and practices: digital technologies and distance education during the coronavirus emergency. Learning, Media and Technology, 45(2), $107-$ 114. https://doi.org/10.1080/17439884.2020.1761641 